This item was submitted to Loughborough's Research Repository by the author.

Items in Figshare are protected by copyright, with all rights reserved, unless otherwise indicated.

\title{
Peer observation of teaching: a decoupled process
}

PLEASE CITE THE PUBLISHED VERSION

http://dx.doi.org/10.1177/1469787411415083

\section{PUBLISHER}

Sage Publications / @ The Authors

\section{VERSION}

AM (Accepted Manuscript)

\section{PUBLISHER STATEMENT}

This work is made available according to the conditions of the Creative Commons Attribution-NonCommercialNoDerivatives 4.0 International (CC BY-NC-ND 4.0) licence. Full details of this licence are available at: https://creativecommons.org/licenses/by-nc-nd/4.0/

\section{LICENCE}

CC BY-NC-ND 4.0

\section{REPOSITORY RECORD}

Chamberlain, J.M., Meriel D'Artrey, and Deborah-Anne Rowe. 2019. "Peer Observation of Teaching: A Decoupled Process". figshare. https://hdl.handle.net/2134/17884. 
Peer observation of teaching: a decoupled process

John Martyn Chamberlain, Meriel D'Artrey and Deborah Anne-Rowe

\title{
Biographical details of authors
}

Dr John Martyn Chamberlain (corresponding author) Loughborough University, Department of Social Science, Leicester LE11 3TU, UK. Email: j.m.chamberlain@lboro.ac.uk. Telephone: 07734886285. Fax: 01509223944.

Marty is a lecturer in criminology and social policy at Loughborough University. Aside from pedagogic research his academic interests include medical regulation and professional malpractice studies.

\section{Ms Meriel D'Artrey}

University of Chester, Department of Social Studies and Counselling, Best Building, Parkgate Road, Chester CH1 4BJ UK. Email: m.dartrey@chester.ac.uk. Telephone: 01244512031. Fax: 01244511342.

Meriel is programme leader for Politics at the University of Chester and is undertaking her professional doctorate in the teaching of political theory. She has a particular interest in student employability skills.

Ms Deborah Anne-Rowe

University of Chester, Department of Social Studies and Counselling, Best Building, Parkgate Road, Chester CH1 4BJ, UK. Email:d.rowe@chester.ac.uk. Telephone: 01244512031. Fax: 01244511342

Deborah worked as a research assistant on the project. She is currently completing her doctoral studies at the University of Chester.

\begin{abstract}
This article details the findings of research into the academic teaching staff experience of peer observation of their teaching practice. Peer observation is commonly used in the United Kingdom higher education sector as a tool to enhance a teacher's continuing professional development. Research participants acknowledged its ability to help develop their teaching practice, but they also reported that it could operate superficially as a tick box exercise, as well as that its outcomes were frequently decoupled from formal staff development processes and its purpose and usefulness therefore seemed unclear. The article argues that the presence of decoupling reinforces the need to account for structural factors that can interact with peer observation of teaching to ensure it is a meaningful exercise for all teaching staff. It concludes that the published academic literature is perhaps guilty of overplaying the role of personal choice and individual tutor characteristics when addressing the complex issue that is staff disengagement with peer observation of teaching.
\end{abstract}

\section{Key Words}

Continuing professional development, higher education, peer observation, staff appraisal, teaching practice, teacher evaluation 


\section{Peer Observation of Teaching (POT): An overview}

This article discusses the findings of research concerned with capturing the academic teaching staff experience of POT. POT typically involves a teacher having one of their teaching sessions observed by a colleague who subsequently provides them with feedback on their performance (Kember 2007). As in other countries worldwide POT can occur within the higher education sector for a number of reasons (Shortland 2004). For example, as a professional requirement for doctors or nurses, as part of a new lecturer's probationary review period, as part of the completion requirements for a PGCert/MA in Learning and Teaching in Higher Education qualification, as well as an annual exercise in ongoing professional development (Bell and Madenovic 2008).

The article focuses on the last of these reasons: where an institution expects its teaching staff to complete POT annually as part of their ongoing continuing professional development activity. But its discussion is arguably also relevant to the other contexts in which POT is applied. Furthermore its content is highly relevant to academics worldwide given growing international concern with economic performance management across the higher education sector as a result of the global recession. Not least of all because this may well yet result in an increased focus being placed on POT as a performance management and career progression tool (Kell and Annetts 2009).

Gosling (2005) has suggested three POT models: 'evaluative', 'developmental' and 'collaborative'. The evaluative model involves making an appraisal of the quality of teaching in order to pass a judgement of standard. POT certainly possesses considerable potential as an evaluative quality assurance and enhancement tool with linkages to career progression mechanisms. This approach operates in some parts of the respective United States of America and Australian higher education systems (Bell 2001). The developmental model involves a more experienced mentor observing a junior to help develop their teaching practice. The collaborative model involves two colleagues working together as equal partners to enhance their teaching practice.

It is generally accepted that POT processes in the United Kingdom higher education sector tend to follow a developmental or collaborative model (Chism 2008). The University and Colleges Union (UCU), the Quality Assurance Agency (QAA) and the Higher Education Funding Council for England (HEFCE) all tend to view POT as a professional development tool, rather than as a formal quality assurance mechanism concerned with policing the performance of teaching staff (Hammersley-Fletcher and Orsmond 2005). Professional regulatory bodies, such as the General Medical Council, also tend to advocate a developmental POT model in relation to the enhancement of teaching practice (Chamberlain 2009). HEFCE (2001:1) have stated that "at its best, teaching observation by peers is a developmental activity, in which peers can openly discuss strengths, weaknesses and developmental priorities without feeling that they are being publically judged in a way that will affect their reputations and careers".

There can be some overlap between the three POT models. It can also be argued that regardless of whether a developmental or collaborative model is followed, the POT process inherently possesses an evaluative element as it involves making value judgements about the quality of teaching practice (Peel 2005). Research shows that POT can make teaching staff feel they are under scrutiny even when a developmental or collaborative POT model is being used (Adshead et al 2006). POT is far from uncontroversial and given the current global economic environment, where there is growing concern over job security amongst academics, the risk of staff suspecting the motives behind the use of POT arguably could stop it from reaching its full potential as a developmental tool (Gosling and Mason O'Connor 2009).

Research on POT from both inside and outside of the higher education sector seems to support the viewpoint that POT can be a valuable developmental tool for enhancing teaching practice (Threlfall and Smith 2001; Kemp and Gosling 2003; Gosling 2005; McMahon et al 2007). Nevertheless it also reinforces the suggestion that teachers may be wary of POT as they often feel it can be overly bureaucratic and possess an underlying competency-based judgemental ethos (Bell 2001; Threlfall and Smith 2001; Kell and Annetts 2009). Certainly 
research has shown that because of their worries teaching staff may seek to avoid it, or do it to comply with institutional policy, rather than because they view it as an opportunity for engaging in beneficial continuing professional development activity (Shorthand 2004).

Lomas and Nicholls (2005) argue that if they are to enhance teaching quality POT schemes need to address staff concerns and be sensitive of their needs. It has been acknowledged that at present POT possesses two key problems because of its singular focus on the observation of teaching practice (Bell and Mladenovic 2008). First, a teacher may deliberately select a particular teaching session for observation that does not necessarily represent their usual teaching practice (Kell and Annetts 2009). They also may pick a "friendly face" to observe them as they know the feedback from this person will be positive (Bell 2001). Second, it is arguably impossible for POT to truly be a developmental process as long as it is restricted to the observation of a single teaching session on an annual basis, as frequently does happen (Knight and Trowler 2001).

It has been argued these issues can be successfully dealt with through providing appropriate guidance and support so staff can make more informed choices concerning both the selection of an observer and which of their teaching sessions they should have observed (Gosling 2005). It is frequently recommended in the literature that new members of staff complete a formal briefing on the POT process to help address any concerns they may have. As well as that members of staff tasked with the observer role should receive some form of formal training to ensure they comply with POT's developmental ethos and handle the observational process in a supportive manner regardless of their relationship with the individual they are observing (Swinglehurst et al 2008).

But providing such support, guidance and training for all academic staff possesses resource implications beyond the ability of some higher education institutions to meet (Kell and Annetts 2009). It has been argued a more viable alternative would be to abandon the requirement for teaching practice to be observed altogether (although a teacher could still choose to be observed if they so wish) and instead require staff engage in a dialogue with a colleague concerning an area of their professional practice they wish to develop (Gosling and Mason O'Connor 2009). It has been said doing this will create an opportunity for teachers to discuss and reflect on a whole range of issues related to learning, teaching and assessment. Such as, for example, "e-learning, course design, writing learning outcomes, learning in practice settings, marking student work, giving feedback and assessing students" (Gosling and Mason O'Connor 2009:5).

A shift in practice away from a sole focus on the observation of teaching may well appear attractive to some academic teaching staff. Yet the fact remains that the academic literature suffers from a lack of empirical research exploring the reasons why some individuals disengage from POT when it is operating under a developmental as opposed to evaluative model (Bell 2001). In the developmental model the POT process is typically decentralized as it tends to be detached from managerial performance appraisal mechanisms and formal career development processes. Rather responsibility for its application and the management of outcomes is typically devolved down from an institutional to an individual level (McMahon et al 2007). Yet the literature remains inconclusive as to if staff anxiety and disengagement with the process in these circumstances is a matter of personal choice and individual teaching philosophy, or is due to other factors, such as having to juggle teaching workloads and research and publication demands (Kell and Annetts 2009).

\section{Research method}

The research aim was to examine the operation of POT. A progressive mixed-method methodology was used, where the validity and reliability of findings is checked throughout the data collection and analysis process via a process of analytical induction, constant comparison and triangulation (Bryman 2006). The research site was chosen as it utilises a devolved developmental POT model where it is expected that members of staff will have their teaching observed once a year by a peer who is provided with guidance on their observer role. Ethical approval to conduct the research study was obtained from the university research ethics committee. The research was divided into three stages. During stage one, which took 
place between September 2009 and November 2009, the research sample was identified. Only academic staff with at least one year service were included in the sample as these individuals should have completed at least one annual POT. Four hundred and three possible research respondents were identified. During stage two, which took place between December 2009 and April 2010, a short questionnaire (see Appendix) that asked staff to anonymously report their experience of POT was finalised through a piloting process consisting of four members of teaching staff and a colleague acting as a 'critical friend' to the project. Stage two ended with the administration of the questionnaire. Questionnaire results fed into stage three, which took place between April and May 2010, and involved randomly selected research volunteers participating in one of three focus groups.

To reinforce the confidential nature of the study the questionnaire did not ask respondents to record key personal characteristics such as their name, teaching speciality, department, age, gender, race or ethnicity. This decision was in part made as a result of feedback obtained via the questionnaire piloting process. This had reinforced the sensitive nature of the research and the wariness felt by some staff toward the topic under investigation. It was felt best to focus in the questionnaire on generating an initial picture of the POT process. So leaving the exploration of the possible impact of more personal factors, such as for example a research participant's gender, for subsequent focus group discussion when a more personal relationship with respondents could be developed (Bryman 2006). That said, it was felt that asking an individual in the questionnaire which teaching faculty their department was based in was far enough removed from them personally to preclude them worrying that they might be personally identified while also providing information which might potentially prove insightful. The same is the case for asking them about their teaching experience in generalizable terms, such as for example, how long they have taught for, or if they possessed any formal educational qualifications.

Eighty four questionnaires were returned from a sample population of four hundred and three. The return rate was twenty one percent. The relatively low response rate was not perceived to be a major cause of concern as it had already been envisaged that questionnaire data would help build an initial snapshot of current practice prior to stage three: the qualitative process of engaging via focus groups in an in-depth dialogue with teaching staff and their self-reported personal experiences of the POT process (Strauss and Corbin 1990). Emphasis was placed upon using the qualitative data collected via focus groups to illuminate the skeleton picture of the conduct of the POT process acquired via the questionnaire.

Sixteen people attended the three focus groups. Each of which lasted over an hour and a half. A transcript was made of the discussion and the research team conducted several sessions in order to manage and to analyse the subsequent material. All respondents were randomly selected from a list of volunteers. To further reassure participants of their anonymity their name, age, gender, teaching position and race and ethnicity were not officially recorded by the project at the focus group stage of the project. However the possibility of such factors influencing the POT process was explored during focus group discussion. Given the confidential nature of the questionnaire completion and focus group volunteering process, it was not possible to know personal characteristics of respondents, such as age and teaching speciality, prior to the focus group taking place. Therefore it was important to gradually building up a picture of the POT process during the focus groups which sought to identify the impact (if any) of such factors on it.

Throughout the data collection and analysis process the research team deliberately and rigorously sought to disprove their developing understanding of the conduct of POT through using respondent validation and framing focus group questions in such a way that informants used their own personal experience to answer them in a either a positive, supporting, or negative, disapproving, sense (Bryman 2006). This process proved invaluable in the final stage of analysis as emergent themes were fully saturated (that is, no new or contradictory data was collected) and linked to an explanatory core theme or central storyline (Strauss and Corbin 1990). This was defined as "decoupling".

\section{Research findings}


This section will first outline some relevant descriptive background data obtained by the project questionnaire before focusing in detail on the conduct of the POT process. Table 1 details respondents by faculty. This shows that the majority of respondents came from Social Science, Health and Social Care and Applied and Health Science faculties, respectively. One respondent did not record their faculty. Although Education and Children Services is perhaps proportionally a little under represented, these relative percentages by and large reflect the comparative size of each faculty at the research site.

$<<$ Insert Table 1 Questionnaire respondents by faculty $>>$

It is important to note that the aim of the research was not to obtain a representative sample mix based on the relative size of each faculty within the research site. Rather, as already discussed, the priority was to maximize the number of questionnaire returns to build an initial picture of the staff experience of the POT process to be subsequently fleshed out during focus group discussion. The value of Table 1 lies in that it shows questionnaire responses were received from each faculty, so each could be represented in the focus groups. This allowed for as broad a picture as possible of the operation of the POT process across the research site given the practical constraints within which it was operating.

Table 2 displays the number of years respondents had taught at the research site. Table 3 displays the number of years respondents had taught in higher education. All eighty four respondents recorded how long they had taught at the research site, but one respondent did not indicate how long they had taught in higher education. This may be because they had only taught at the research site. Taken together these Tables show that responses were obtained from a broad range of teaching staff, whose practical higher education teaching experience ranged from between two and forty three years, and who had taught at the research site for between one and twenty eight years.

$\ll<$ Insert Table 2 Years respondents have taught at research site $\gg>$

$<<$ Insert Table 3 Years respondents have taught in higher education $>>$

Tables 2 and 3 show that the majority of respondents could be classified as experienced higher education teachers. The average number of years respondents had taught for in higher education was 13.7 ( 8.6 at the research site). The most common response was 8 ( 5 at the research site). Table 4 shows that some respondents also had experience of working in other educational sectors, most commonly in further education. The category "other" includes respondents who reported that they had taught outside of the UK, had been involved in adult/community education, or who had been involved in the clinical teaching of nurses.

$<<$ Insert Table 4 Teaching experience in other educational sectors $>>$

Table 5 shows that in addition to having a range of teaching experience, a number of respondents possessed an educational qualification. Included under the "other" category are respondents who indicated that they possessed a Masters degree in health professional education, had a New York City board education teaching licence, were a registered nurse teacher, or had a further/adult education teaching certificate. It is perhaps unsurprising that the most frequent educational qualification cited by respondents was a PGCert in Learning and Teaching in Higher Education as most universities in the UK now require teaching staff complete this type of qualification. 
$\ll<$ Insert Table 5 Respondents educational qualifications >>

Taken together the background information contained in Tables 1 to 5 shows that the individuals came from a range of academic disciplines and tended to be relatively experienced teachers, some of whom had taught outside of the higher education sector. Arguably this means respondents were ideally positioned to comment on the POT process and its utility as a tool for enhancing professional development. But it was not possible to identify clear statistical trends between this background information and respondents experience of the POT process. This is perhaps unsurprising given the relatively small questionnaire return rate. Yet this should not be taken to mean that the research did not identify thematic relationships between a teacher's academic background and their experience of the POT process. As will shortly be discussed, focus group respondents reported that variation existed in how some departments approached POT.

$<<$ Insert Table 6 Had respondents attended a POT training event? >>

It is important to identify how many respondents had completed some form of formal introduction to the POT process used at the research site. Table 6 shows the majority of respondents reported that they had not received a formal introduction to the POT process as it operated at the research site. Only nineteen percent of respondents had attended a formal introduction to POT. Table 7 shows that the POT process did not take place annually for all academic teaching staff. Twenty three percent of respondents indicated that they had not had their teaching observed in the last year. A further eleven percent of respondents did not answer this question.

$<$ Insert Table 7 Had respondents been observed in the last year? >>

Sixty six percent of staff who indicated that POT had happened in the last year reported that they had used the university guidance and paperwork associated with the POT process. Six percent of respondents did not answer this question. Twenty eight percent of respondents had not used the approved university guidance and paperwork when completing the POT process. Instead they had used "home made" guidance and resources provided by their heads of department.

$<<$ Insert Table $8 \mathrm{Had}$ respondents used university guidance and paperwork? >>

Taken together Tables 7 and 8 show that nineteen of the eighty four questionnaire respondents reported they had not had their teaching observed in the last year. Furthermore, sixteen of those who had been observed had not used the associated university guidance and paperwork. Twelve respondents did not reply to these questions. Only forty four percent of all respondents ( $n=37$ of 84 respondents) reported that they had been observed in the last year using the recommended POT guidance and paperwork.

Only fifty four percent of questionnaire respondents reported that they felt completing the POT process had identified clear opportunities for addressing issues relevant to their continuing professional development. Yet it was also clear that respondents did see how POT could benefit their teaching practice. As focus group participants commented:

"the discussion afterwards, it was actually very beneficial, very positive to identify what I needed to do differently." (Focus group participant)

"... it encourages the reflective practitioner I think above all because if you know someone is going to come and watch you, whether you respect or don't respect them, you're going to reflect about your own practice..." (Focus group participant) 
Although some staff felt the POT process could be beneficial, even those who were positive about it argued that staff engagement toward it varied and on occasion it was being approached in a superficial form-filling manner. That is, they considered it a "tick box exercise", meaning that they went through the process of ticking boxes on a form but paid superficial attention to what they were doing and why they were doing it. As one focus group participant put it, "it's about lip-service, compliance, having to do...". Furthermore, focus group discussion revealed that the attitudes of heads of department toward POT could influence the nature of staff engagement with it. Participants felt that while some departmental heads made it clear that they expected teaching staff to complete the process, others either ignored it completely or paid it very little regard. They felt quite strongly that different academic departments within the university's teaching faculties approached POT differently, with some appearing to approach the process more rigorously than others. This may well be because some disciplines, such as teacher training for example, have more practical experience of the use of POT as a professional development and quality enhancement tool. Although it was not possible to statistically verify across the university campus which departments were which, it was certainly clear across the focus groups that a variance in practice did indeed exist. For example, respondents felt that some departments within the Education and Children Service Faculty adopted a more rigorous stance toward POT than some departments within the Social Science Faculty.

It was apparent from the focus groups that emphasis was being placed by some members of staff on complying with institutional requirements to complete the POT process rather than on engaging with it as a continuing professional development tool. Variance in practice between some departments seemed to contribute to this. It also appeared that if a head of department had clear managerial expectations surrounding teaching staff engagement with POT then this could positively influence a participant's experience of the process. Yet it was similarly clear that although heads of department played an important role in the application of POT, they were not the key determining factor influencing staff engagement with it. Indeed it became clear as the focus groups progressed that in the eyes of research participants two interrelated "structural factors" were heavily influential in staff disengagement with the POT process.

Firstly, research participants felt ambiguity existed regarding the purpose of POT. In no small part this was due to an apparent lack of focus on following up POT outcomes. POT outcomes can range from the recognition of teaching excellence to the highlighting of possible areas for continuing professional development activity with a view to enhancing the student learning experience. The underlying concern here for research participants was inadequate resourcing for staff development and a sense that the university management and administrative structure seemed to be uncertain of the aim of POT. As one focus group participant put it, "I think...the main weakness as far as I'm concerned is that it doesn't know what it is. Well, just what is its purpose? What does the university see as its purpose?". Bound up with this was a need for clarity regarding the role of the stakeholders within the POT process. Particularly when dealing with problems, if they arose. Research participants were concerned that currently there seemed to be no administrative structure in place at a university-wide level to refer to other than existing formal management processes such as disciplinary hearings. To their mind this situation seemed at odds with the developmental ethos underpinning POT. As one argued, "if there is a genuine problem with that member of staff, maybe there is something that could be a consequence of what they're doing, or it may be a behaviour that they are experiencing that they don't know how to handle and they don't know where to ask for help.... There isn't really anywhere to go with it".

Secondly, and underlying this apparent lack of a supporting structure, was the fact that at present the POT process is more often than not "decoupled" from more formal staff development processes. This made its purpose and usefulness unclear. Forty six percent respondents reported in their questionnaires that the outcomes of the POT process had not been discussed at their annual staff development interview. Furthermore, only twenty one percent of respondents who indicated in their questionnaire that POT outcomes had been discussed at their staff development interview were subsequently advised by their head of department of possible opportunities for continuing professional development to address the issues raised by the POT process. Both teaching staff and heads of department seemed 
unclear as to how POT outcomes should be taken forward. This may well be why focus group participants argued that decoupling was a key barrier to the success of POT and therefore it may be necessary to "re-couple" it with the annual staff development review process:

"I'd like to see it linked in with the staff development interview process. So that when you are running the staff development interview you actually have some facts to actually support that discussion." (Focus group participant)

In conclusion, the research identified a degree of ambivalence amongst some members of staff toward POT due to its potential to act as a workforce surveillance and performance management tool. However other members of staff were positive about the POT process and reported it helped them develop their professional practice. As one focus group participant put it, "my experience of it [POT] has always been supportive and has not been threatening". The key finding of the research was not staff ambivalence or non-compliance toward POT. Nor was it that practice seemed to vary between academic departments, with some approaching POT more rigorously than others. Rather, the key finding was that a lack of clarity of communication regarding the purpose of POT, alongside the decoupling of the process from formal staff review processes, appeared to be playing a significant role in encouraging some staff to adopt a superficial stance of "paperwork compliance" toward POT.

\section{Discussion and conclusion}

The results of this study corroborate that found in the literature, namely, that practice can often vary between academic departments when a decentralised and devolved developmental POT model is used (Gosling 2005). Perhaps as would be expected the research also found that academic teaching staff can be wary of POT as they can feel it to be overly bureaucratic and possess an underlying competency-based judgemental ethos (Kemp and Gosling 2003; Kell and Annetts 2009). But the key finding of research was that a structural factor - namely, the lack of formal linkages between POT outcomes and more formal staff review processes - played an important role in influencing teaching staff engagement with POT.

It is arguable that if the research had taken place at a university where they had been a degree of "joined-up thinking" between the POT process and the annual staff review process then research participants may have been significantly more concerned that POT could act as an evaluative rather than developmental tool. It also needs to be acknowledged that the relatively small scale nature of the research and the low questionnaire return rate makes the generalizability of the research findings presented somewhat circumspect. Likewise it must be acknowledged that there is a possibility that research respondents were engaging in a "blame game" with university management to excuse instances of their own and their colleagues' disengagement with POT. These limitations are acknowledged. However, the research generated a conceptual picture that can act as a useful heuristic sensitising device for other researchers to utilise when analysing the application of POT in other contexts. At the same time it is acknowledged that more research is needed to further verify and extend the findings presented. Comparative research in other higher education institutions with academic teaching staff and university management is needed to more fully explore decoupling.

The results reinforce that the academic literature is perhaps guilty of overplaying the role of personal choice and individual tutor characteristics, such as a willingness and ability to engage in reflective practice for example, when addressing the complex issue that is staff disengagement with POT (Peel 2005). There is a clear need to examine decoupling further as it is arguably an inherent feature of the developmental POT model. It may be necessary to recouple POT with an academic's annual development review meeting with their head of department. During which they could discuss the outcomes of the POT process and what support they now need to help them with their continuing professional development needs.

Further research and critical reflection is needed before such an approach can be adopted. Not least of all because formalising POT in this way could open it up to the criticism that there is too much potential for managerial involvement within what is meant to be a developmental 
process. Nevertheless it should be possible to introduce a more formalised support structure and ability to follow up of POT outcomes without undermining the developmental principles that underpin it. Furthermore such a shift in practice may be unavoidable if Gosling and Mason O'Connor's (2009) new POT model, with its focus upon dialogue as opposed to observation, is to evolve out of current practice at a time when the broader economic climate may yet lead to the developmental POT model being replaced by a more evaluative one.

\section{Acknowledgements}

The research team would like to take this opportunity to thank all the individuals whose participation made this research possible.

\section{References}

Adshead L, White P and Stephenson A. (2006) Introducing peer observation of teaching to GP teachers Medical Teacher 28 (2): 68 - 73

Allen, L (2001) Guidelines for higher education branches: peer review and observation of teaching, NATFHE, London.

Bell, M (2001) Supported reflective practice: a programme of peer observation and feedback for academic teaching development International Journal for Academic Development 61: 29 39

Bell, A and Madenovic, R. (2008) The benefits of peer observation of teaching for tutor development Higher Education 55: 735 - 752

Bryman, A. (2006 second edition) Social research methods Oxford University Press

Chamberlain, J.M. (2009) Portfolio-based appraisal: superficial or useful? British Journal of Hospital Medicine 70 (11): 176 - 177.

Chism, N.V.N. (2008) Peer CARE, Peer-CARE Newsletter 1 December 2008 Singapore Management University

Cosh, J. (1999) Peer observation: a reflective model ELT Journal 53 (1): 22 - 27

Gosling, D. (2005) Peer observation of teaching SEDA Paper 118 Birmingham: SEDA

Gosling, D and Mason O'Connor, K. (2009) Beyond the peer observation of teaching SEDA paper 124 London: SEDA

Hammersley-Fletcher, L and Orsmond, O. (2005) Reflecting on reflective practice within peer observation Studies in Higher Education 30 (2): 213 - 224

Kell, C and Annetts, S. (2009) Peer review of teaching: embedded practice or policy-holding complacency? Innovations in Education and Teaching International 46 (1): 61 - 70

Kemp, R and Gosling, D. (2003) Peer observation of teaching (Downloaded $31^{\text {st }}$ August from http://escalate.ac.uk/)

Knight, P and Trowler, P. (2001) Departmental leadership in higher education: new directions for communities of practice Buckingham: Open University Press

Lomas, L and Nicholls, G. (2005) Enhancing teaching quality through peer review of teaching Quality in Higher Education 11 (2): 137 - 149

McMahon, T, Barrett, T and O'Neil, G. (2007) Using observation of teaching to improve quality: finding your way through the muddle of competing conceptions, confusion of practice and mutually exclusive intentions Teaching in Higher Education 12 (4): 499 - 511

Peel, D. (2005) Peer observation as a transformatory tool? Teaching in Higher Education 10 (4): $489-504$

Shortland, S. (2004) Peer observation: a tool for staff development or compliance? Journal of Further and Higher Education 29(2): 219 - 228

Strauss, A.L and Corbin, J.M. (1990) Basics of qualitative research: grounded theory procedures and techniques Sage Publications

Swinglehurst, D, Russell, J and Greenleigh, T. (2008) Peer observation of teaching in the online environment: an action approach Journal of Computer Assisted Learning 24: $383-393$ Threlfall, J and Smith, L. (2001) The nature and benefits of peer observation: summary produced for the TTA/DFEE London: Department for Education and Employment 
Table 1 Questionnaire respondents by faculty

\begin{tabular}{|l|r|}
\hline \multicolumn{1}{|c|}{ Faculty } & \% of respondents \\
\hline Applied and Health Sciences & $21.4 \%$ \\
\hline Arts and Media & $9.5 \%$ \\
\hline Health and Social Care & $19.3 \%$ \\
\hline Business, Enterprise and Lifelong Learning & $7.2 \%$ \\
\hline Education and Children's Services & $8.4 \%$ \\
\hline Humanities & $6.0 \%$ \\
\hline Social Science & $25.3 \%$ \\
\hline Learning and Teaching Institute & $2.4 \%$ \\
\hline No response & $1 \%$ \\
\hline & $100 \%$ \\
\hline
\end{tabular}

Table 2 Years respondents have taught at research site

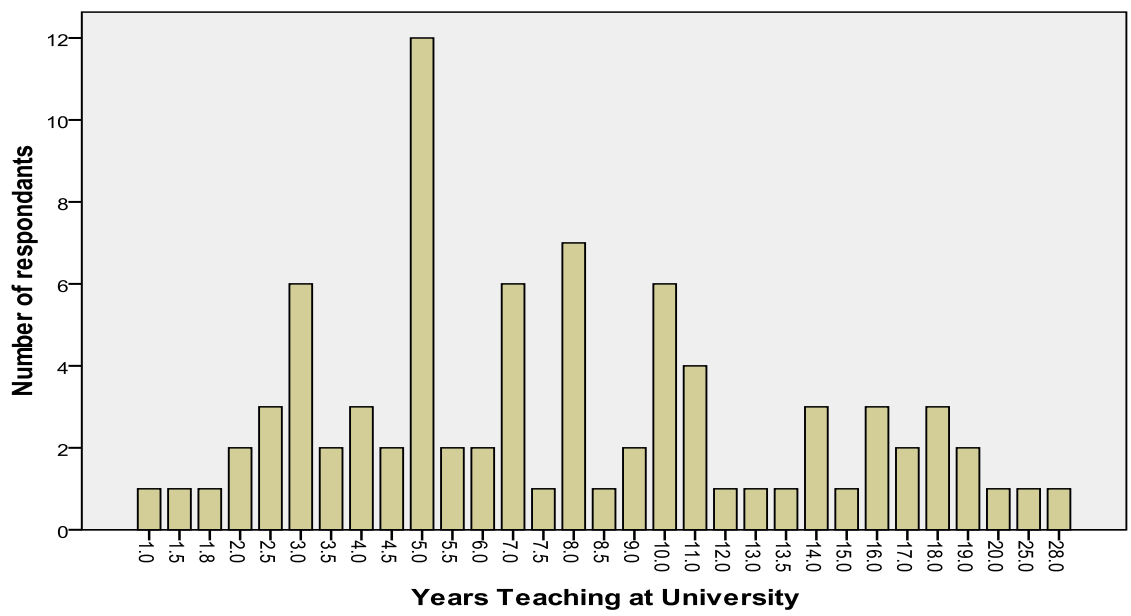

Table 3 Years respondents have taught in higher education

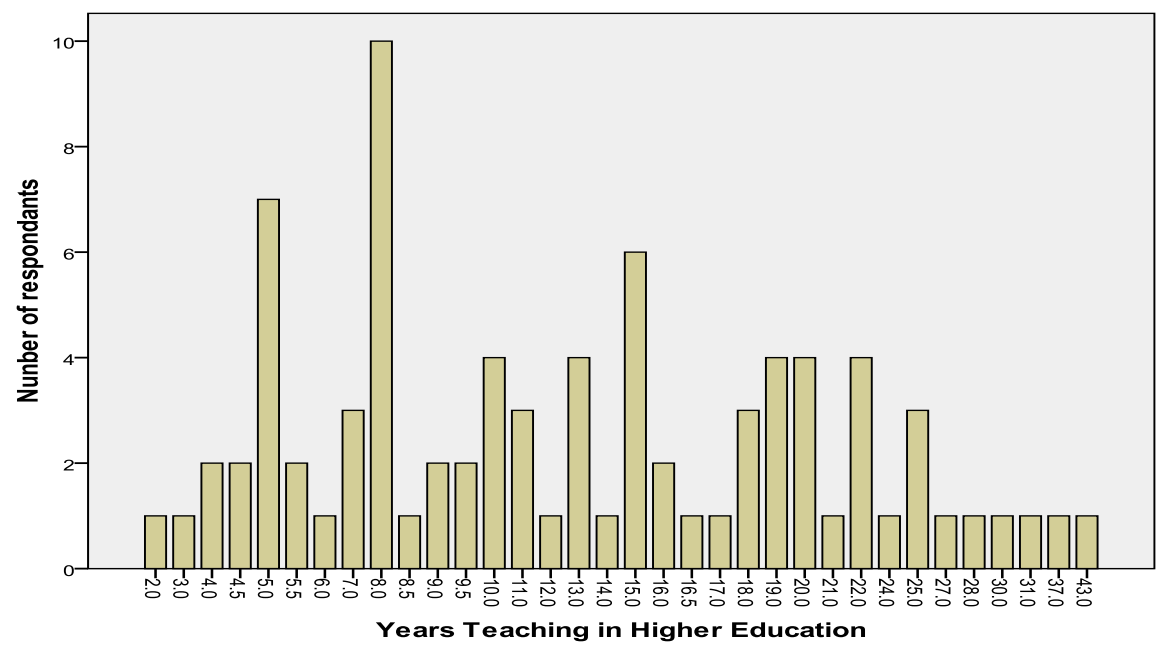


Table 4 Teaching experience in other educational sectors

\begin{tabular}{|l|r|}
\hline \multicolumn{1}{|c|}{ Teaching Sector } & \multicolumn{2}{c|}{$\begin{array}{c}\text { Number of } \\
\text { Respondents }\end{array}$} \\
\hline Primary Education & 4 \\
\hline Secondary Education & 14 \\
\hline Vocational Education & 6 \\
\hline Further Education & 26 \\
\hline Other & 11 \\
\hline
\end{tabular}

Table 5 Respondents educational qualifications

\begin{tabular}{|l|l|}
\hline \multicolumn{1}{|c|}{ Qualification } & $\begin{array}{l}\text { Number of } \\
\text { Respondents }\end{array}$ \\
\hline B.Ed Teaching Qual & 7 \\
\hline PGCE Teaching Qual & 8 \\
\hline PGCert T\&L Higher Education & 28 \\
\hline PGDip T\&L Higher Education & 5 \\
\hline Masters T\&L Higher Education & 3 \\
\hline Taught Educational Masters Degree & 12 \\
\hline Research Educational Masters Degree & 2 \\
\hline PhD in Educational topic & 6 \\
\hline Other Teaching/Educational Qual & 7 \\
\hline
\end{tabular}

Table 6 Had respondents attended a POT training event?

\begin{tabular}{|l|l|l|}
\hline $\begin{array}{l}\text { Attended POT } \\
\text { training event? }\end{array}$ & $\begin{array}{l}\text { Number of } \\
\text { respondents }\end{array}$ & $\%$ \\
\hline Yes & 16 (of 84) & $19 \%$ \\
\hline No & 64 (of 84) & $76 \%$ \\
\hline No Response & 4 (of 84) & $5 \%$ \\
\hline
\end{tabular}

Table $7 \mathrm{Had}$ respondents been observed in the last year?

\begin{tabular}{|l|l|l|}
\hline $\begin{array}{l}\text { Observed in } \\
\text { last year? }\end{array}$ & $\begin{array}{l}\text { Number of } \\
\text { respondents }\end{array}$ & $\%$ \\
\hline Yes & 56 (of 84) & $66 \%$ \\
\hline No & 19 (of 84) & $23 \%$ \\
\hline No Response & 9 (of 84) & $11 \%$ \\
\hline
\end{tabular}

Table $8 \mathrm{Had}$ respondents used university guidance and paperwork?

\begin{tabular}{|l|l|l|}
\hline $\begin{array}{l}\text { Used university } \\
\text { documents? }\end{array}$ & $\begin{array}{l}\text { Number of } \\
\text { respondents }\end{array}$ & $\%$ \\
\hline Yes & 37 (of 56) & $66 \%$ \\
\hline No & 16 (of 56) & $28 \%$ \\
\hline No Response & 3 (of 56) & $3 \%$ \\
\hline
\end{tabular}




\section{Questionnaire}

1. To which faculty are you affiliated (please feel free to tick more than 1 box if necessary).

Applied and Health Sciences [ ] Arts and Media [ ] Health and Social Care [ ] Business, Enterprise and Lifelong Learning [ ] Education and Children's Services [ ] Humanities [ ] Social Science [ ]

2. How many years, including fixed term and temporary teaching positions, have you taught at this university?

3. How many years, including fixed term and temporary teaching positions, have you taught in higher education?

4. Please indicate if you have ever taught for at least one year in any of the following teaching sectors (please feel free to tick more than 1 box if necessary).

Primary Education [ ] Secondary Education [ ] Further Education [ ] Vocational Education [ ] Other (please specify)

5. Please indicate if you possess any of the following teaching qualifications (please feel free to tick more than 1 box if necessary).

B.Ed. [ ] Post Graduate Certificate of Learning and Teaching in Higher Education [ ] Post Graduate Diploma of Teaching and Learning in Higher Education [ ] Masters of Teaching and Learning in Higher Education [ ] Other (please specify)

6. Please indicate if you currently possess any of the following higher degree qualifications (please feel free to tick more than 1 box if necessary).

Taught Masters of Education [ ] Research Masters of Education [ ] $\mathrm{PhD}$ on Educational Topic [ ] Other education-related higher degree (please specify)

7. Have you ever attended a university staff development event on any aspect of the peer observation of teaching process.

Yes [ ] (If yes please give details below) No [ ]

8. Does your department currently make peer observation an annual requirement?

Yes [ ] (If yes please give details below) No [ ]

9. Have you used the instruments provided by the university for its peer observation scheme?

Yes [ ] If yes please give details.

No [ ] If no please describe method(s)/instruments used in peer observation process 
10. Have the outcomes of peer observation of your teaching identified clear opportunities for addressing issues relative to your continuing professional development in relation to teaching and learning?
Academic year
2008-2009
$\begin{array}{rr} & \text { (Please tick) } \\ \text { Yes [ ] } & \text { No [ ] }\end{array}$

Please use this space to provide further comments if you wish:

11 Have you discussed outcomes of your participation in the peer observation of teaching process with your head of department during your annual staff development interview?

Academic year

2008-2009

$$
\begin{array}{rr} 
& \text { (Please tick) } \\
\text { Yes [ ] } & \text { No [ ] }
\end{array}
$$

Please use this space to provide further comments if you wish:

12 Have you been offered opportunities for continuing professional development by your head of department to address issues identified as an outcome of peer observation?
Academic year
(Please tick)
2008-2009

Yes [ ] No [ ]

Please use this space to provide further comments if you wish:

13 Please use the space provided for any further comments you wish to make.

Thank you for your participation.

Please return the questionnaire using the envelope provided. 